John H.R. Burns et al.

\title{
Investigating the spatial distribution of Growth Anomalies affecting Montipora capitata corals in a 3- dimensional framework
}

\author{
Author Information \\ J. H. R. Burns (corresponding author) \\ Department of Biology, College of Natural Sciences. University of Hawai ‘ i at Mānoa \\ 2538 McCarthy Mall, Edmondson Hall Room 216. Honolulu, HI 96822, USA \\ Phone: 808-854-4057 \\ Fax: 808-933-0423 \\ Email: johnhr@hawaii.edu \\ T. Alexandrov \\ Structural and Computational Biology, European Molecular Biology Laboratory \\ Meyerhofstraße 1, 69117 Heidelberg, Germany \\ E. Ovchinnikova \\ Structural and Computational Biology, European Molecular Biology Laboratory \\ Meyerhofstraße 1, 69117 Heidelberg, Germany \\ R. D. Gates \\ Hawai 'i Institute of Marine Biology, University of Hawai ‘i at Mānoa \\ PO Box 1346, Kaneohe, HI 96722, USA
}

M. Takabayashi

Marine Science Department, University of Hawai 'i at Hilo

200 W. Kawili St., Hilo, HI 96720, USA

(C) 2016. This manuscript version is made available under the Elsevier user license http://www.elsevier.com/open-access/userlicense/1.0/ 
John H.R. Burns et al.

\begin{abstract}
Diseases have caused significant reductions in coral populations throughout the global ocean. Despite a substantial effort to thoroughly characterize the epizootiology and etiology of coral diseases, little is known about the distribution and spatial clustering and of disease lesions on affected coral colonies. This study investigated spatial clustering of the coral disease, growth anomaly (GA), which exhibits high levels of prevalence and severity in Montipora capitata and other corals at Wai'ōpae, southeast Hawai'i Island. Like many other coral diseases, the patterns of disease spread and transmissibility of GA remains unknown. We utilized cutting-edge 3D reconstruction techniques to map the precise spatial distribution of GAs on affected coral colonies. Three statistical measures, Ripley's K, Moran's I, and the Kolmogorov-Smirnov test were used to determine if the GA lesions were distributed in a non-random pattern. Each measure showed the GA lesions exhibited distinct spatial clustering on all ten affected colonies analyzed in this study. Our study is not only the first 3D analysis of intra-colony disease clustering, but also provides a novel approach for investigating and quantifying the level of disease clustering in order to improve our understanding of coral disease epizootiology, transmission, and etiology.
\end{abstract}

Keywords: Coral; disease; growth anomaly; disease clustering; 3D modeling; structurefrom-motion 
John H.R. Burns et al.

\section{Introduction}

Disease is considered a primary factor in the decline of coral communities throughout the world's oceans. The frequency and spread of coral diseases has increased dramatically over the last several decades, and in some cases, diseases are primary drivers of overall reef degradation (Harvell et al. 1999, Green and Bruckner 2000, Goldberg and Wilkinson 2004, Harvell et al. 2007). Investigations into the causative factors of coral diseases suggest that increases in outbreaks and the prevalence of diseases associate with environmental stressors such as increased seawater temperature, sedimentation, overfishing, pollution and eutrophication (Hughes 1994, Hoegh-Guldberg 1999, Bruno et al. 2003, Harvell et al. 2007). The mortality caused by coral disease can have profound effects on the community composition, structure and function of coral reef ecosystems (Green and Bruckner 2000, Weil et al. 2006, Alvarez-Filip et al. 2011). Multiple studies have suggested that coral diseases are infectious, however, Koch's postulates have not been fulfilled for those coral diseases that are believed to involve an infectious agent (Work and Meteyer 2014). Determining if diseases are indeed transmissible or infectious is a critical step towards identifying the mechanisms that drive disease prevalence and severity.

Infectious diseases can be caused by pathogenic microorganisms such as bacteria, viruses, protozoans, or fungi, and contagious diseases are transmitted through direct or indirect contact (Stedman 1976). Infectious diseases may not be contagious and it is 
John H.R. Burns et al. important to make this distinction in order to develop coral-disease models capable of accurately assessing population susceptibility. For investigating the contagious nature of a disease, spatial epidemiology statistically examines if diseased individuals exist in a spatially clustered pattern. Clustering of diseased individuals suggests a contagious mode of transmission if an infectious agent causes the disease. In contrast, spatially random distributions of diseased individuals suggests that a disease is likely not contagious (Marshall 1991, Wartenberg 2001, Emch et al. 2012, Muller and van Woesik 2012). Previous studies have examined the spatial clustering of corals affected by aspergillosis, black-band disease, yellow-band syndrome, dark spot syndrome, and white-band disease across spatial scales ranging from meters to kilometers (Jolles et al. 2002, Foley et al. 2005, Zvuloni et al. 2009, Lentz et al. 2011, Muller and van Woesik 2012). In some cases the affected colonies were found to exhibit spatial clustering, leading to a conclusion that the disease clusters indicated localized transmission driven by environmental stressors (Jolles et al. 2002, Zvuloni et al. 2009). These studies provide useful epizootiological information to understand the mechanics of how a disease-causing agent spreads at the population scale, yet few studies have examined if corals diseases are clustered or transmitted within affected colonies. Coral diseases may be contagious and transmitted among the polyps of an affected colony, as perforate corals are essentially a dense population of genetically similar individuals, polyps, which are physically connected by gastrovascular tissue. Determining the communicable nature of coral diseases has proved difficult due to the complex interactions among the pathogens, hosts, and the 
John H.R. Burns et al.

environment (Harvell et al. 1999). Characterizing the spatial distribution of disease lesions can provide useful information for elucidating the etiology and epizootiology of diseases affecting corals.

GA is a coral disease first described in 1965 that affects multiple coral species on reefs throughout the world's oceans (Squires 1965, Peters et al. 1986, Vargas-Angel 2009). The morphology of this disease is characterized by protuberant skeletal growth, pale appearance, and loss of polyp structure (Bak 1983, Gateno et al. 2003, Burns et al. 2011). Histological investigations have identified hyperplasia of the basal body wall and a reduction in critical cellular features as innate characteristics of this disease, thus elucidating that GA affects critical biological functions such as reproduction, feeding, digestion, defense, and energy acquisition (Work and Rameyer 2005, Work et al. 2008, Burns and Takabayashi 2011, Burns et al. 2013). To date, no microbial studies have successfully identified any pathogen or infectious agent associated with GA (DomartCoulon et al. 2006). Only one study has experimentally tested direct and indirect transmission of this disease between colonies, which found two of sixteen healthy colonies to develop multiple GAs from direct contact and one of sixteen colonies developed a single GA lesion via indirect contact (Kaczmarsky and Richardson 2007). Characterizing the spatial distribution patterns of the GA lesions on affected colonies may provide valuable insight for understanding the biology of this disease.

The population of the coral, Montipora capitata, at Wai'ōpae, southeast Hawai'i Island, displays an exceptionally high level of GA prevalence and severity compared to 
John H.R. Burns et al.

other sites throughout the Hawaiian archipelago, and thus presents a unique opportunity to study GA spatial distribution (Aeby 2004, Takabayashi et al. 2010, Burns et al. 2011). This study tested the hypothesis that GAs affecting $M$. capitata at Wai'ōpae exhibit clustered spatial distribution patterns. Innovative three-dimensional (3D) reconstruction techniques were utilized to accurately map the spatial distribution of GA lesions on diseased colonies in a 3D framework. This is the first study to use computer vision techniques to assess disease distribution on corals. Three statistical procedures were used in combination with statistical simulation to assess GA spatial distribution patterns and determine if the lesions exhibit spatial clustering: Ripley's K function, Moran's I, and the Kolmogorov-Smirnov test. Examining the spatial distribution of GA on M. capitata provides valuable insight into the epizootiology of this disease, and is useful in directing future research to determine etiology and exposure pathways.

\section{Methods}

\subsection{Photographing GA-affected Montipora capitata colonies}

Images were collected at Wai'ōpae (19²9’55” N 15449’06” W), southeast Hawai'i Island, using methods developed specifically for creating 3D reconstructions of underwater coral reef habitats (Burns et al. 2015). Ten M. capitata colonies of similar size ( 1-m diameter) were selected that exhibited a GA severity (relative percent cover) of at least $15 \%$ in order to adequately capture potential lesion clustering (Figure 1a,b). Ground control points (GCPs) were placed around each photographed colony, and the 
John H.R. Burns et al.

depths and relative distances among the GCPs were recorded to create $\mathrm{x}, \mathrm{y}, \mathrm{z}$ reference coordinates for the modeled substrate. A calibration grid and a scale marker were placed adjacent to each photographed colony to validate accuracy and precision of the resulting 3D models. Photographs were taken from planar and oblique angles to acquire overlapping images that captured the entire surface area of each colony. Photos were taken using a Pentax K-5 digital SLR camera with an 18-55 mm lens (PENTAX RICOH Imaging Americas Corporation, USA) in an Ikelite housing (Ikelite Underwater Systems, Indianapolis, Indiana, USA). An 8-inch hemispheric dome port was used for the Ikelite housing to reduce refraction and enhance the ability of the software to accurately align the images (Bruno et al. 2011, McCarthy \& Benjamin 2014).

\subsection{D reconstruction and digital annotation of GAs}

The GA-affected colonies were rendered in 3D using Agisoft PhotoScan (Agisoft LLC.) modeling software. PhotoScan calibrated the images with Brown's distortion model, which resolves optical characteristics of the camera lens using information derived from the image metadata. PhotoScan uses several algorithms to detect invariant features from the overlapping images in order to create geometrical projective matrices and determine the exact position and orientation of the camera for each sequential image (Verhoeven et al. 2012, Westoby et al. 2012). Extrinsic and intrinsic camera parameters linked the pixel coordinates of the image points with the corresponding coordinates in the camera reference frame to construct 3D geometry on the $2 \mathrm{D}$ image plane (Stal et al. 
John H.R. Burns et al.

2012). Iterative bundle adjustments refined the 3D coordinates of the scene geometry, which minimized re-projection error in order to create a sparse 3D point cloud that accurately represented each photographed colony. Photo alignment was optimized within the PhotoScan software using the known $\mathrm{x}, \mathrm{y}, \mathrm{z}$ values of the GCPs in order to ensure spatial accuracy of the resulting 3D models. Once the photo alignment and sparse point cloud were optimized, a dense point cloud was generated and used to construct a triangulated surface mesh. The surface mesh was rendered with the sequential images to create high-resolution textured 3D digital surface models for each of the GA-affected $M$. capitata colonies (Figure 1c-e). The textured 3D models were reviewed in PhotoScan, and digital markers were manually placed onto each individual GA lesion on the affected colonies (Figure 1f). The x,y,z coordinates of the GA lesions were exported from PhotoScan and used to quantify the pairwise distances among the lesions on each colony surface. 3D colony models were exported as Virtual Reality Modeling Language (VRML) files and collated with the lesion coordinates in MATLAB (MathWorks, MA, USA) in order to statistically analyze the spatial distribution of this disease on the affected colonies.

\subsection{Statistical Analysis}

GA lesions were mapped onto the 3D VRML model of each colony by assigning the closest vertex to each lesion. A random configuration of points across the colony surface was generated by randomly sampling them from the VRML vertices with the number of 
John H.R. Burns et al. spots equal to the number of the GA lesions in the colony. Random configurations were simulated to statistically test the null hypothesis that the GA lesions exhibit random distribution. Three statistical measures were employed to assess global clustering of the disease lesions on the affected coral colonies: Ripley's K, Moran's I, and KolmogorovSmirnov's test $p$-value.

Ripley's K (Ripley, 1976) is a descriptive statistic for detecting deviations from spatial randomness. The function $K(t)$, where $t$ is the search radius, is defined as

$$
K(t)=\lambda^{-1} \sum_{i \neq j} I\left(d_{i j}<t\right) / n
$$

where $\mathrm{d}_{\mathrm{ij}}$ is the Euclidean distance between the $\mathrm{i}^{\text {th }}$ and $\mathrm{j}^{\text {th }}$ points in a data set of $n$ points, $\lambda$ is the average density of points (estimated as $n / A$, where $A$ is the area of the region containing all points) and $I$ is the indicator function ( 1 if its operand is true, 0 otherwise). In line with the conventional use of Ripley's K in ecography (Lancaster and Downes 2004), the analysis was performed on 2D X-Y projections of the 3D VRML vertices and lesion spots. We used the Ripley's K function to quantify the difference between the configurations of the GA lesions and 1000 randomly simulated configurations (Figure 2).

For this, we defined a statistic maxdiffK as the normalized maximal difference between Ripley's K of the GA lesions and of the random configurations:

$$
\operatorname{maxdiff} K=\frac{\max _{t}\left(\max \left(k_{\min }(t)-K_{G A}(t), K_{G A}(t)-K_{\max }(t), 0\right)\right)}{\max _{t}\left(K_{G A}(t)\right)}
$$


John H.R. Burns et al. where $K_{G A}(t)$ is the $\mathrm{K}$ function for the GA lesions and $K_{\min }(t)$ and $K_{\max }(t)$ are the minimal and maximal values of Ripley's K for all random configurations at the search radius $t$. Larger values of maxdiffK correspond to a greater difference between the distribution of GA lesions and the simulated random distributions. In our calculations of Ripley's $\mathrm{K}, t$ was selected to have 20 equidistant values from 0 to $t_{\max }$, where $t_{\max }$ was calculated as a maximum of the $\mathrm{X}$ size of the colony, $\mathrm{Y}$ size of the colony, and maximal pairwise Euclidean distance between GA lesions. Ripley's K can be calculated with or without edge correction. The aim of the edge correction is to adjust the values for points that are close to the boundary (edge) of the area where events are observed. In our study, no edge correction was used, as the correction is not recommended for spatial point pattern analysis (Lancaster and Downes 2004).

Moran's I (Moran, 1950) is a statistical measure of local spatial autocorrelation defined as

$$
I=\frac{N}{\sum_{i} \sum_{j} w_{i j}} \frac{\sum_{i} \sum_{j} w_{i j}\left(X_{i}-\bar{X}\right)\left(X_{j}-\bar{X}\right)}{\sum_{i}\left(X_{i}-\bar{X}\right)^{2}}
$$

where $N$ is the number of spatial units indexed by $i$ and $j$ (in this case a unit is a vertex of the colony mesh); $X$ is the variable of interest (whether a vertex was annotated as having a lesion); $\bar{X}$ is the mean of $X$ (across all vertices); and $w_{i j}$ are spatial weights used to numerically represent neighboring relationships. We defined the neighborhood based on distance, so that spatial weight $w_{i j}$ was defined to be equal to 1 if the Euclidean distance 
John H.R. Burns et al. between $i$ 'th and $j$ 'th vertices is less than a specific threshold; otherwise, it is equal to 0 . Typically the Moran's I is calculated on a X-Y plane where spatial units are assumed to have the same area and a signal is defined as a quantity of events in a spatial unit. Since this set up is not directly applicable to a 3D mesh, a spatial unit was defined to be a vertex of the $3 \mathrm{D}$ mesh and the weights $w_{i j}$ encode for the neighborhood property. The mesh of each colony was reduced to 10000 faces to enable calculations as the Moran's I algorithm has $O\left(N^{2}\right)$ computational complexity, where $N$ is the number of vertices. A threshold of 0.05 was selected as it delivered the maximal average-across-colonies Moran's I value. Finally, similarly to the Ripley's K analysis, we introduced a statistic maxdiffI as the maximal difference between Moran's I values of the distribution of GA lesions and of the 100 simulated random configurations.

In addition to the conventional statistics of Ripley's K and Moran's I, we also utilized the Kolmogorov-Smirnov (K-S) test (Smirnov, 1948), which provides a method for statistically comparing pairwise distances. We used the pairwise Euclidean distances between the GA lesions as a proxy for evaluating the randomness of their configuration. For each of the 1000 randomly simulated configuration, the distances between the spots in the configuration were compared by means of the K-S test to the distances between the GA lesions, resulting in a p-value. Altogether, 1000 p-values were calculated for each colony (one for each random configuration) and their mean and median values were calculated. The smaller these values are, the more different the spatial distribution of GA 
John H.R. Burns et al.

lesions is from a random distribution. All the GA lesion coordinates, VRML models, and scripts for spatial statistical analyses are available (Burns et al. Data in Brief submitted).

\section{Results}

The Ripley's K values for GA spatial distribution on all ten examined colonies were larger than the Ripley's K values derived from the simulations of random distributions, which indicates that the observed GA distributions were spatially clustered (Tables $1 \& 2$ ). Colony 5848 exhibited the strongest spatial clustering, as indicated by the large Ripley's K values, and Colony 7040 displayed the weakest degree of spatial clustering.

Results from Moran's I analysis showed all colonies to exhibit autocorrelation, with colony 5848 exhibiting the strongest degree of clustering in comparison to the simulations of random distribution, and colony 7040 exhibiting the least amount of clustering (Table 1). The Moran's I values for the simulated random distributions were a few orders of magnitude smaller than those of the distribution of GA lesions. The average (median) value of Moran’s I among all colonies was $0.000539207( \pm 0.00000015)$ for random configurations, and $0.023113114( \pm 0.02152005)$ for the distribution of GA lesions (Table 1). The reported maxdiffI values were approximately equal to the Moran's I values for the distribution of GA lesions (Table 1).

The Kolmogorov-Smirnov (K-S) test showed the distribution of GAs to be nonrandom for all colonies. All p-values for all colonies were below the significance level 
John H.R. Burns et al.

equal to 0.00005 (calculated as 0.05 divided by 1000, the number of random

configurations, to account for multiple testing following the Bonferroni correction). Both the mean and median of $\mathrm{p}$-values were low (with the maximal-across-colonies values to be equal to $7.00 \mathrm{E}-20$ and $8.00 \mathrm{E}-40$ for the mean and median p-values, accordingly). This indicates all GA distributions were significantly different from the simulated random distributions (Table 1).

\section{Discussion}

It is important to develop methods capable of accurately characterizing coral disease epizootiology, as disease poses a major threat to reef ecosystems around the globe (Richardson 1998, Harvell et al. 1999, Harvell et al. 2007, Zvuloni 2009, De'ath et al. 2012). This study analyzed the spatial distribution of a coral disease, growth anomaly (GA), affecting Montipora capitata colonies at Wai`ōpae, southeast Hawai`i Island. We utilized 3D reconstruction techniques to accurately map the distribution of GA lesions in ten affected colonies (Figure 1), and used three spatial statistical approaches to determine if this disease exhibited an inhomogeneous spatial distribution pattern at the coral colony scale. Analyzing GA distribution in this novel 3D framework enabled the first assessment of disease clustering across the 3D surface of individual coral colonies. The techniques presented in this study provide a method for accurately mapping the spatial distribution of disease lesions across coral colony surfaces. Utilizing 3D reconstructions enabled us to perform Moran's I and K-S analysis in 3D, rather than on 2D X-Y projections as is more conventional in spatial descriptive analyses (Lancaster and Downes 2004). Although the 
John H.R. Burns et al.

potential of using a 3D approach is still to be revealed, it is natural to expect that it is better suited to quantify spatial properties on such a complex 3D surface as a coral colony. The SfM reconstruction technique captures imagery from all angles of the colony surface and is highly accurate (mm-scale). The resulting models enable detailed inspection of the GA lesions, and the annotations provide precise Euclidean and geodesic coordinates that could not be captured in the field or with simple 2D image analysis. Exploiting the geodesic rather than 3D Euclidean (as in this study) distance may provide another angle on the spatial characteristics of GA as it provides a better approximation of the lesion distribution throughout the colony surface. However, the state-of-the-art algorithms for calculating geodesic distance have computational complexity of $O\left(N^{2}\right.$ $\log N)$ that makes it impractical for large 3D surface meshes, especially for repeated simulation experiments as in this study.

Using the above technique, we examined whether the spatial distribution of GA lesions is random or clustered to a degree of statistical significance. Disease clustering is often due to infectiousness, thus the examination of spatial clusters can provide valuable information for determining etiology and mechanisms of disease transmission (Marshall 1991, Wartenberg 2001). For all M. capitata colonies examined, the GA distribution patterns were significantly different from the simulated random distributions as evaluated by the p-values of the Kolmogorov-Smirnov (K-S) test (Table 1). Further applying the Ripley's K and Moran's I statistics showed that the degree of clustering varied in strength among the ten affected colonies, but all the GA lesions displayed distinctly 
John H.R. Burns et al.

inhomogeneous distribution in each case (Figure 2, Table 1). The maxdiffI values indicate that both the scale and strength of GA lesion clustering exhibits variability throughout the surface of the examined colonies (Figure 2). The clustering analyses in this study utilized a global approach, and specifically tests whether or not the distribution of all GA lesions is clustered. Future studies could employ a local approach to determine if there are specific regions of affected colonies where clusters occur, which may help to explain the observed variability in the scale of GA clustering.

Spatial clustering is a hallmark signature for the presence of localized disease transmission (Zvuloni 2009, Emch 2012). The clustering of GA lesions on all ten affected colonies suggests that further investigation into the communicable nature of this disease is warranted. Temporal examination of lesion distribution in the future will likely elucidate if the GA lesions spread throughout the colony after a possible initial infection. $M$. capitata are perforate corals, and thus all the individual polyps are connected through the gastrovascular cavity. While such anatomy renders transmission among polyps possible, our results are limited to the evidence that the GA lesions exhibit statistically significant spatial clustering. The spatial clustering of disease lesions indicates that a contagious mode of transmission is likely (Marshall 1991, Wartenberg 2001, Muller and van Woesik 2012), yet direct transmission experiments and isolation of etiological agents are required to determine if this disease is both infectious and communicable.

An intra-colony mechanism of transmission explains some of the documented disease characteristics at Wai‘ōpae (Takabayashi et al. 2010, Burns et al. 2011, Burns and 
John H.R. Burns et al.

Takabayashi 2011). Wai'ōpae experiences a high frequency of both chronic (e.g. geothermally heated groundwater, tourism and recreation impacts) and acute (e.g. elevated seawater temperatures, agricultural runoff, wastewater contamination) local stressors that may serve as triggers for disease (Takabayashi et al. 2010, Burns et al. 2011, Wiegner et al. 2016). These local environmental stressors and disturbances can provoke physiological and biochemical responses in the corals, as well as changes to the associated microbial communities, that can contribute to the occurrence of disease (Bourne 2009). Intra-colony transmission may explain the high severity and abundance of GA lesions on affected colonies that reside in close proximity or directly adjacent to colonies showing no signs of disease at Wai‘ōpae (Burns and Takabayashi 2011). Coupling a broader analysis of direct and indirect transmission of this disease with a temporal evaluation of GA spread will provide valuable insight into the communicable nature of this disease.

\section{Conclusion}

Marine ecosystems in Hawai'i are currently being exposed to increasing levels of global (e.g. climate change, coral bleaching) and local stressors (e.g. land-based pollution, over-fishing, coastal development) (Harvell et al. 1999), and due to isolation and high levels of endemism, the health and function of coral reefs in Hawai' $i$ are inherently susceptible to these harmful environmental disturbances (Tissot et al. 2009). It is critical to thoroughly characterize diseases as well as investigate the association of 
John H.R. Burns et al.

environmental factors and disease risk in order to develop effective management strategies to protect and conserve Hawaiian coral reefs. Our research approach presents a useful technique for assessing the clustering of disease within individual affected coral colonies. While spatial epizootiology cannot determine precise causality of a disease, it provides important and useful scientific information for further investigations into disease etiology (Wartenberg 2001). The results from this study are limited to identifying the clustering spatial distribution of GA lesions, however, these findings support the utility of further investigation into transmission dynamics and potential pathogenic agents to better characterize the biology of this disease. 
John H.R. Burns et al.

\section{Acknowledgements}

This publication was developed under STAR Fellowship Assistance Agreement no. FP-

91768001-0 awarded by the U.S. Environmental Protection Agency (EPA). It has not been formally reviewed by the EPA. The views expressed in this publication are solely those of the authors and EPA does not endorse any products or commercial services mentioned in this publication. Funding was also provided by the National Science Foundation Center for Research Excellence in Science and Technology (Grant No. 0833211) for the Center in Tropical Ecology and Evolution in Marine and Terrestrial Environments, by the ESPCoR Hawai'i (EPS-0903833) research grant and by the European Union's Horizon2020 and FP7 programs under the grant agreements No. 634402, 305259. We thank Kanoe Steward and for assistance with fieldwork. 
John H.R. Burns et al.

\section{References}

Aeby GS (2004) Baseline levels of coral disease in the Northwestern Hawaiian Islands. In: Northwestern Hawaiian Islands 3rd Scientific Symposium, 2-4 November 2004. NOAA National Marine Fisheries Service Pacific Islands Fisheries Science Center, Honolulu

Alvarez-Filip L, Dulvy NK, Cote IM, Watkinson AR, Gill JA. 2011. Coral identify underpins architectural complexity on Caribbean reefs. Ecological Applications 21(6):2223-2231

Bourne DG, Garren M, Work TM, Rosenberg E, Smith GW, Harvell CD (2009) Microbial disease and the coral holobiont. Trends in Microbiology 17(12):554-562

Brownell AC, Richardson LL (2014) Sulfate reducing bacteria as secondary and necessary pathogens in black band disease of corals. Rev Biol Trop 62: 1-9

Bruno F, Bianco G, Muzzupappa M, Barone S, Razionale AV. 2011. Experimentation of structured light and stereo vision for underwater 3D reconstruction. ISPRS Journal of Photogrammetry and Remote Sensing 66:508-518

Bruno JF, Petes LE, Harvell CD, Hettinger A (2003) Nutrient enrichment can increase the severity of coral diseases. Ecology Letters 6:1056-1061

Burns JHR, Rozet NK, Takabayashi M (2011) Morphology, severity, and distribution of growth anomalies in the coral, Montipora capitata, at Wai'ōpae, Hawaii. Coral Reefs 30: $819-826$ 
John H.R. Burns et al.

Burns JHR, Takabayashi M (2011) Histopathology of Growth Anomaly Affecting the Coral, Montipora capitata: Implications on Biological Functions and Population Viability. PLoS ONE 6(12): e28854

Burns JHR, Gregg TM, Takabayashi M (2013) Does Coral Disease AffectSymbiodinium? Investigating the Impacts of Growth Anomaly on Symbiont Photophysiology. PLoS ONE 8(8): e72466

Burns JHR, Delparte D, Gates RD, Takabayashi M. (2015) Integrating structure-frommotion photogrammetry with geospatial software as a novel technique for quantifying 3D ecological characteristics of coral reefs. PeerJ 3:e1077

Burns JHR, Alexandrov T, Ovchinnikova E, Gates RD, Takabayashi T (submitted) Spatial statistical analysis of Growth Anomaly lesions on Montipora capitata coral colonies using 3D reconstruction techniques. Data in Brief

De'ath, G., Fabricius, K. E., Sweatman, H., and Puotinen, M. (2012). The 27-year decline of coral cover on the Great Barrier Reef and its causes. Proc. Natl. Acad. Sci. U.S.A. 109, 17995-17999

Domart-Coulon IJ, Traylor-Knowles N, Peters E, Elbert D, Downs CA, et al. (2006) Comprehensive characterization of skeletal tissue growth anomalies of the finger coral Porites compressa. Coral Reefs 25: 531-543

Emch E, Root ED, Giebultowicz S, Ali M, Perez-Heydrich C, Yunus M (2012) Integration of spatial and social network analysis in disease transmission studies. Ann Assoc Am Geogr. 2012 ; 105(5): 1004-1015 
John H.R. Burns et al.

Foley JE, Sokolow SH, Girvetz E, Foley CW, Foley P (2005) Spatial epidemiology of Caribbean yellow band syndrome in Montastraea spp. coral in the eastern Yucatan, Mexico. Hydriobiology, 548, 33-40

Friedlander A, Aeby G, Brainard R, Clark A, DeMartini E, Godwin S, Kenyon J, Kosaki R, Maragos J, Vroom P (2005) The state of coral reef ecosystems of the Northwestern Hawaiian Islands. The State of Coral Reef Ecosystems of the United States and Pacific Freely Associated States: 2005. Northwest Hawaiian Islands Chapter. Technical memo. National Ocean Service, Center for Coastal Monitoring and Assessment, Silver Spring, MD

Goldberg J, Wilkinson C (2004) Global threats to coral reefs: coral bleaching, global climate change, disease, predator plagues, and invasive species. Status of Coral Reefs of the World 2004:67-92

Green EP, Bruckner AW (2000) The significance of coral disease epizootiology for coral reef conservation. Biol Conserv 96:347-361

Harvell CD, Kim K, Burkholder JM, Colwell RR, Epstein PR, Grimes DJ, Hofmann EE, Lipp EK, Osterhaus AD, Overstreet RM, Porter JW, Smith GW, Vasta GR (1999) Emerging Marine Diseases, Climate Links and Anthropogenic Factors. Science 285:1505-1510

Harvell CD, Jordan-Dahlgren E, Merkel S, Rosenberg E, Raymundo L, Smith G, Weil E, Willis B (2007). Coral disease, environmental drivers and the balance between coral and microbial associates. Oceanography 20: 58-81 
John H.R. Burns et al.

Hoegh-Guldberg O (1999) Climate change, coral bleaching and the future of the world's coral reefs. Mar Freshw Res 50:839-866

Hughes TP (1994) Catastrophes, phase Shifts, and large-scale degradation of a Caribbean coral reef. Science 265:1547-1551

Jolles AE, Sullivan P, Alker AP, Harvell CD (2002) Disease transmission of aspergillosis in sea fans: inferring process from spatial pattern. Ecology, 83, 2373-2378

Kaczmarsky L, Richardson LL (2007) Transmission of growth anomalies between IndoPacific Porites corals. J Invert Pathol 94: 218-221

Lancaster J, Downes BJ (2004) Spatial point pattern analysis of available and exploited resources. Ecography 27:94-102

Lentz JA, Blackburn JK, Curtix AJ (2011) Evaluating patterns of a white-band disease (WBD) outbreak in Acropora palmata using spatial analysis: a comparison of transect and colony clustering. PLoS ONE, 6, 1-10, e21830, doi: 10.1371/journal. pone. 0021830

Marshall RJ (1991) A review of methods for the statistical analysis of spatial patterns of disease. Journal of the Royal Statistical Society. Series A (Statistics in Society) 154(3): 421-441

McCarthy J, Benjamin J. 2014. Multi-image photogrammetry for underwater archaeological site recording: an accessible, diver-based approach. Journal of Maritime Archaeology 9:95-114

Moran PA (1950). Notes on continuous stochastic phenomena. Biometrika, 17-23. 
John H.R. Burns et al.

Peters EC, Halas JC, McCarty HB (1986) Calicoblastic neoplasms in Acropora palmate, with a review of reports on anomalies of growth and from in corals. J Natl Cancer Inst 76: 895-912

Richardson LL (1998) Coral diseases: what is really known? Trends Ecol. Evol., 13: pp. 438-443

Ripley BD (1976). The second-order analysis of stationary point processes. Journal of applied probability, 255-266.

Smirnov N (1948). Table for estimating the goodness of fit of empirical distributions. The annals of mathematical statistics, 279-281.

Stal C, Bourgeois J, De Maeyer P, De Mulder, De Wulf GA, Goossens R, Hendrickx M, Nuttens T, Stichelbaut B (2012) Test case on the quality analysis of structure from motion in airborne applications. Proceedings of the 32nd EARSeL Symposium: 'Advances in Geosciences,' Mykonos, Greece, May 21-24, P.11

Stedman TL (1976) Stedman's Medical Dictionary. Williams and Wilkin Company, Baltimore, $1079 \mathrm{p}$.

Squires DF (1965) Neoplasia in a coral? Science 148: 503-505

Takabayashi M, Gregg TM, Farah E, Burns J, Teves K, Cody NH (2010) The prevalence of skeletal growth anomaly and other afflictions in scleractinian corals at Wai'ōpae, Hawai'i. Proc $11^{\text {th }}$ Int Coral Reef Symp 18:820-824 
John H.R. Burns et al.

Tissot BN, Walsh WJ, Hixon MA (2009) Hawaiian islands marine ecosystem case study: Ecosystem- and community-based management in Hawaii. Coastal Management $37: 255-273$

Vargas-Angel B (2009) Coral health and disease assessment in the US Pacific remote island areas. Bull Mar Sci 84: 211-227

Verhoeven G, Doneus M, Briese C, Vermeulen F (2012) Mapping by matching: a computer vision-based approach to fast and accurate georeferencing of archaeological aerial photographs. Journal of Archaeological Science, 39: 2060-2070

Wartenberg D (2001) Disease clusters: Why, when and how? Journal of the Royal Statistical Society. Series A (Statistics in Society) 164(1): 13-22

Wiegner TN, Mokiao-Lee AU, Johnson EE (2016) Identifying nitrogen sources to thermal tide pools in Kapoho, Hawaii, USA, using a multi-stable isotope approach. Marine Pollution Bulletin available online doi:10.1016/j.marpolbul.2015.12.046

Weil E, Smith G, Gil-Agudelo DL (2006) Status and progress in coral reef disease research. Dis Aquat Org 69:1-7

Westoby MJ, Brasington J, Glasser NF, Hambrey MJ, Reynolds JM (2012) ‘Structurefrom-Motion' photogrammetry: A low-cost, effective tool for geoscience applications. Geomorphology 179:300-314

Work TM, Rameyer RA (2005) Characterizing lesions in corals from American Samoa. Coral Reefs 24: 384-390 
John H.R. Burns et al.

Work TM, Aeby GS, Coles SL (2008) Distribution and morphology of growth anomalies in Acropora from the Indo-Pacific. Dis Aquat Org 78: 255-264

Work TM, Meteyer CU (2014) To understand coral disease, look at coral cells. Ecohealth. 11:610-618

Zvuloni A, Artzy-Randrup Y, Stone L, Kramarsky-Winter E, Barkan R, Loya Y (2009) Spatio-temporal transmission patterns of black-band disease in a coral community. PLoS ONE, 4, 1-10, e4993, doi: 10.1371/journal.pone.0004993 
John H.R. Burns et al.

\section{Table and figure legends}

Figure 1. a) Montipora capitata colony that exhibits at least $15 \%$ severity (proportion of colony surface area occupied by lesions) of growth anomaly (GA). b) Multifocal GA lesions exhibit distinct morphology (pale protuberant masses) compared to normal colony tissue. The GA lesions are spatially mapped by reconstructing overlapping images of each affected colony into a c) 3D point cloud, which is then triangulated to create a d) continuous surface mesh that is integrated with the high-resolution images to develop the e) textured mesh model with is f) annotated to determine $x, y, z$ coordinates for each GA lesion.

Figure 2. Annotated 3D VRML models for each affected colony with accompanying Ripley's K configuration range calculated from 1000 random simulations. Curves are presented for the GA lesions (red), all simulated configurations (grey), Kmin (blue), and Kmax (green). Maxdiff is indicated for each curve to indicate the search radius at which the GA lesion distribution exhibits the strongest spatial clustering.

Table 1. Results for each statistical test used to examine the spatial distribution of GA lesions on ten affected Montipora capitata coral colonies. 
John H.R. Burns et al.

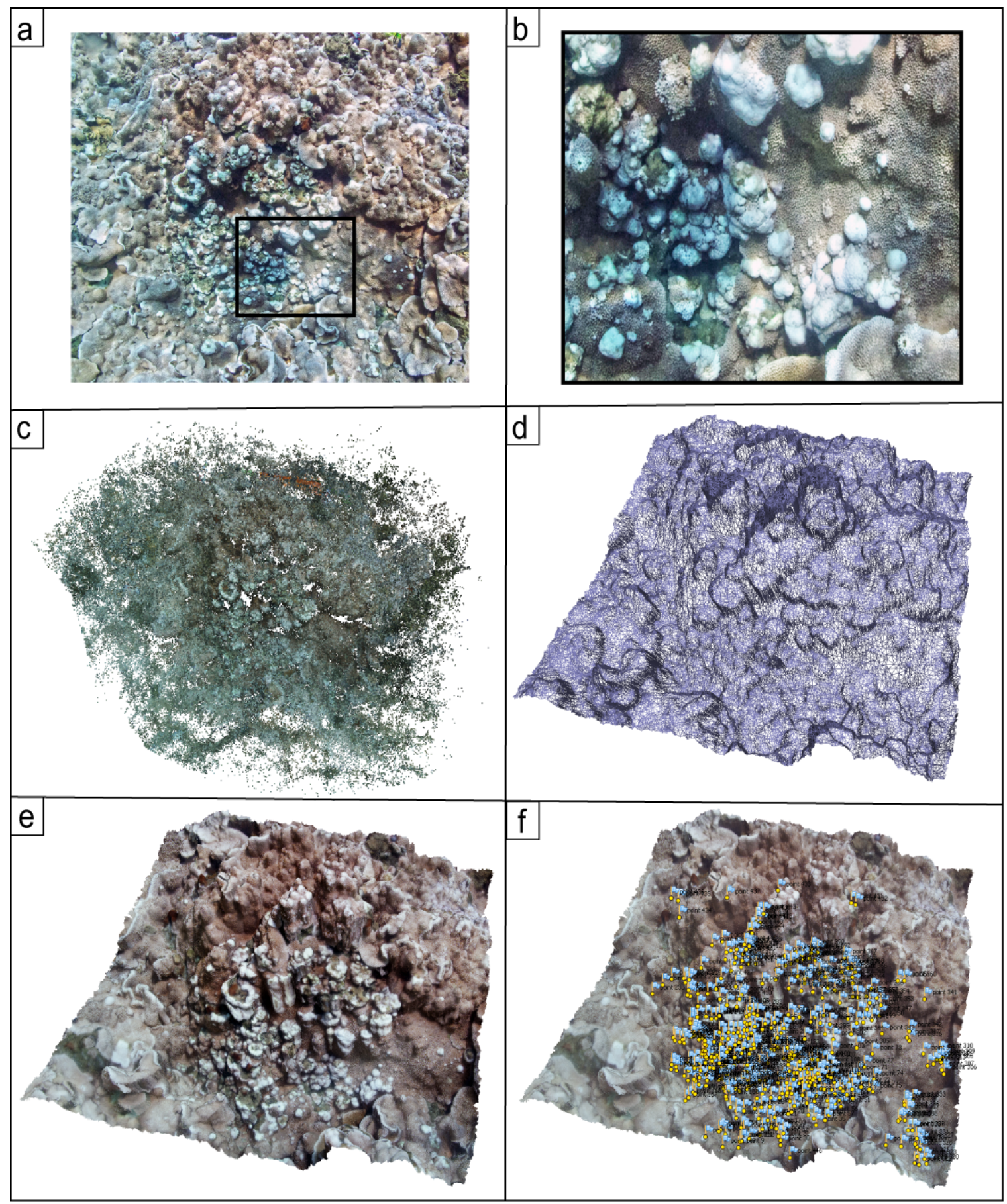


John H.R. Burns et al.

\begin{tabular}{|c|c|c|c|}
\hline Annotated 3D model & Ripley's K results & Annotated 3D model & Ripley's K results \\
\hline 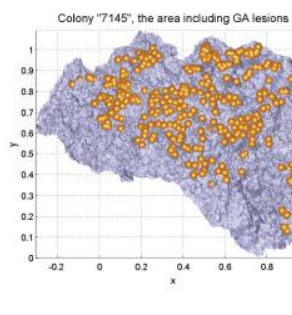 & 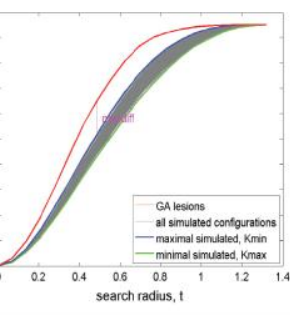 & 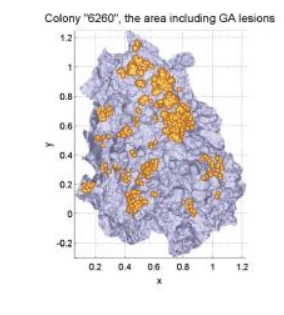 & 1) \\
\hline 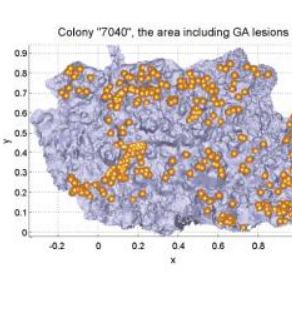 & 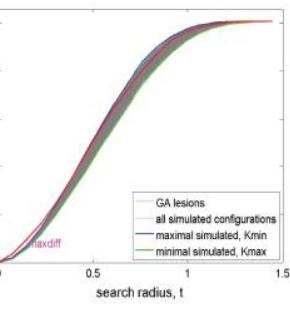 & 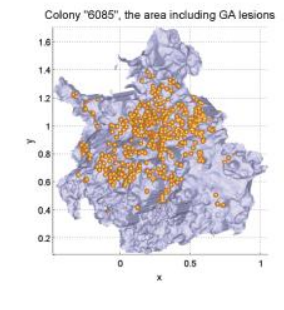 & 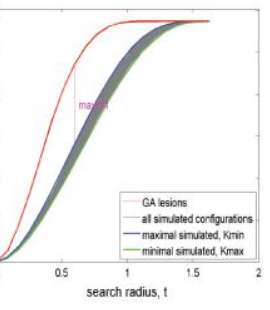 \\
\hline 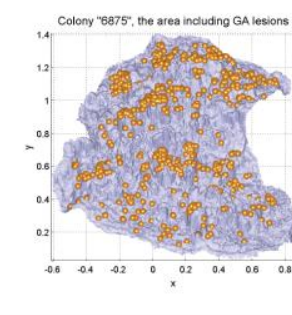 & 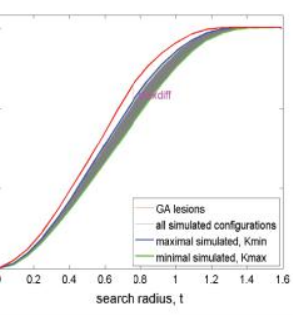 & 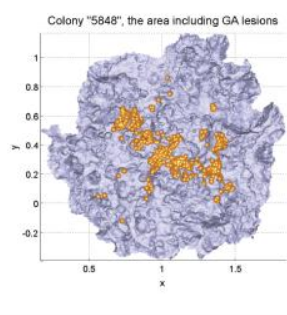 & 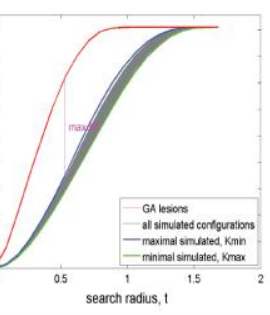 \\
\hline Colony " 8717 , the area indudng GA lestions & 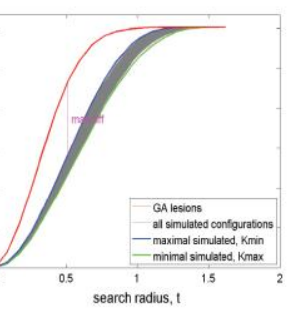 & 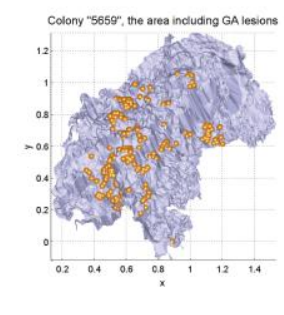 & 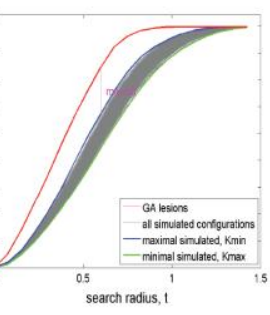 \\
\hline 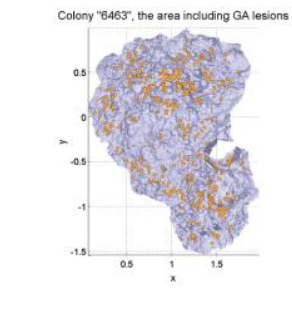 & i. & 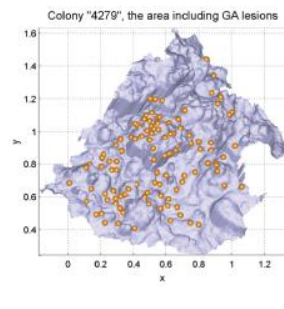 & 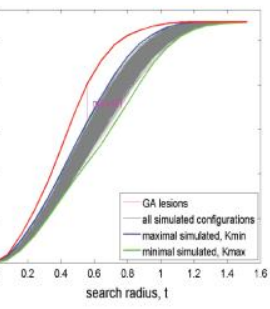 \\
\hline
\end{tabular}


John H.R. Burns et al.

Table 1

\begin{tabular}{|c|c|c|c|c|c|}
\hline \multirow[t]{2}{*}{ Colony ID } & \multicolumn{3}{|c|}{ Kolmogorov-Smirnov Test } & \multirow{2}{*}{$\begin{array}{c}\text { Ripley's K } \\
\text { max diff }\end{array}$} & \multirow{2}{*}{$\begin{array}{c}\text { Moran's I } \\
\text { threshold } 0.5\end{array}$} \\
\hline & $\begin{array}{l}\text { mean } p- \\
\text { value }\end{array}$ & $\begin{array}{l}\text { median } p- \\
\text { value }\end{array}$ & $\begin{array}{c}\text { ratio of significant } \\
\text { p-values }\end{array}$ & & \\
\hline 7040 & $2.00 \mathrm{E}-20$ & $1.00 \mathrm{E}-38$ & $100 \%$ & 0.03 & 0.0131981 \\
\hline 6463 & $6.00 \mathrm{E}-86$ & $1.00 \mathrm{E}-195$ & $100 \%$ & 0.05 & 0.0131981 \\
\hline 6875 & $1.00 \mathrm{E}-252$ & 0 & $100 \%$ & 0.07 & 0.0193818 \\
\hline 7145 & 0 & 0 & $100 \%$ & 0.14 & 0.0193818 \\
\hline 4279 & $2.00 \mathrm{E}-79$ & $2.00 \mathrm{E}-181$ & $100 \%$ & 0.16 & 0.00282284 \\
\hline 6260 & 0 & 0 & $100 \%$ & 0.19 & 0.0412488 \\
\hline 5659 & $1.00 \mathrm{E}-207$ & 0 & $100 \%$ & 0.19 & 0.0236583 \\
\hline 6717 & 0 & 0 & $100 \%$ & 0.31 & 0.0244505 \\
\hline 6085 & 0 & 0 & $100 \%$ & 0.33 & 0.0303635 \\
\hline 5848 & 0 & 0 & $100 \%$ & 0.41 & 0.0469419 \\
\hline $\begin{array}{l}\text { non- } \\
\text { randomness } \\
\text { indicated by: }\end{array}$ & \multicolumn{2}{|c|}{ low value } & high value & high value & high value \\
\hline
\end{tabular}


John H.R. Burns et al.

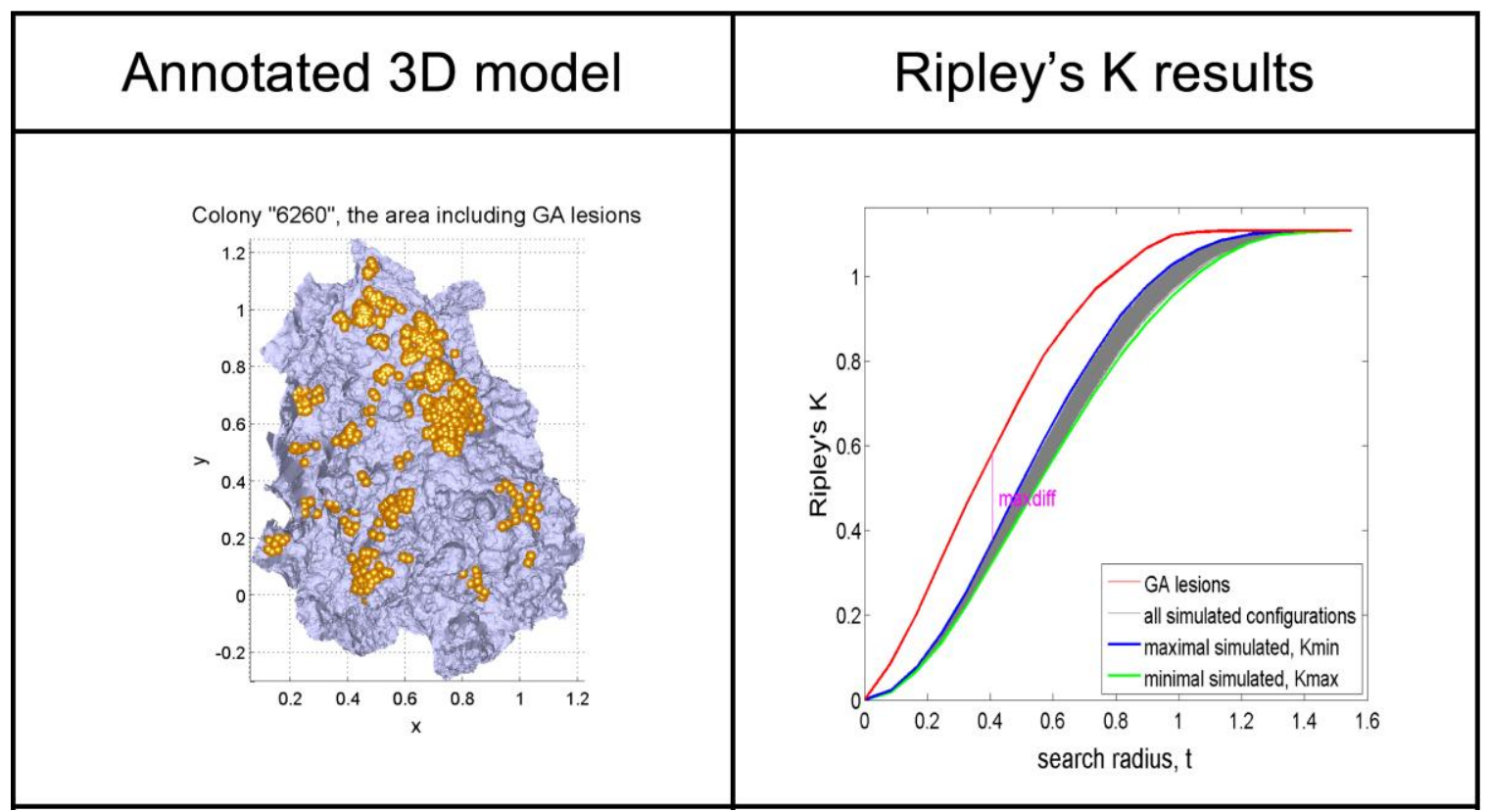

